\title{
Medication-overuse headache. Retrospective comparison of preventive treatments
}

\author{
Cefaleia por uso excessivo de medicamentos. Comparação retrospectiva \\ de tratamentos preventivos
}

\author{
Abouch V. Krymchantowski1, Ana Gabriela Ferreira Krymchantowski', Carla da Cunha Jevoux ${ }^{1}$
}

\begin{abstract}
Objectives: Medication-overuse headache is commonly seen in tertiary centers. Limited evidence is available regarding treatment. We compared the use of one or two drugs, three drugs, or four pharmacological agents for the prevention of headache. Methods: This was a retrospective analysis of 149 consecutive patients. Sudden withdrawal and pharmacological prevention with one or more drugs were carried out. Adherence and the decrease of headache frequency of more than $50 \%$ were compared after four months between the one or two, three, and four drug groups. Results: There was no difference in adherence ( $p>0.6)$. Headache frequency reduction was shown in 23 (54.8\%, one or two drugs), 33 (70\%, three drugs) and 11 (55\%, four drugs); $p=0.13$ and $p=0.98$, not significant. There was a tendency towards significance between the one or two drug takers versus the three drug and four drug takers together $(p=0.09)$. Conclusions: The use of more drugs was not better at improving headache. However, there is the possibility that acting simultaneously on different sites may promote broader modulation and better outcome.
\end{abstract}

Keywords: Medication-overuse; headache; migraine; treatment.

RESUMO

Objetivos: Cefaleia por uso excessivo de medicamentos (CEM) é comum em centros terciários. Existe evidência limitada quanto a estratégias de tratamento e se combinar drogas é melhor do que abordagens com monoterapia. Objetivamos comparar o uso de até dois, três ou quatro agentes farmacológicos para a prevenção. Métodos: Estudo retrospectivo de 149 pacientes consecutivos. A suspensão súbita das drogas usadas em excesso e o início de prevenção foram realizados. A adesão e a redução superior a 50\% na frequência da cefaleia foram comparadas após quatro meses entre até duas drogas, três drogas e quatro drogas. Resultados: A adesão não foi diferente ( $p$ > 0.6). A redução da frequência de cefaleia foi de 23 (54.8\%, até duas drogas, 33 (70\%, três drogas) e 11 ( $55 \%$, quatro drogas; $p=0.13$ e $p=0.98$, não significativo). Houve uma tendência à significância quando comparamos até duas drogas com três e quatro drogas ( $p=0.09$ ). Conclusões: Não demonstramos superioridade de mais drogas, comparando-se a um ou dois medicamentos. Acreditamos na possibilidade de atuação em sítios de diferentes de forma simultânea e a modulação mais abrangente com melhores parâmetros evolutivos.

Palavras-chave: Cefaleia por uso excessivo de medicamentos; enxaqueca; migrânea; tratamento.

Medication-overuse headache is a prevalent, disabling disorder among headache sufferers seeking treatment in neurological clinics ${ }^{1,2}$. Although it occurs in less than $3 \%$ of the population, medication-overuse headache may represent most of the headache patients from tertiary centers ${ }^{1,2}$. It is a subset of daily or near-daily headache occurring from or during the overuse of symptomatic medications, especially in patients with migraine or chronic migraine as their primary headache $e^{2,3,4}$. Despite the troublesome burden to the sufferers and the recent knowledge about possible mechanisms of its pathophysiology, very little evidence is available regarding treatment strategies, the real need for initiating preventive medications and whether combining drugs is better than approaches with monotherapy for the prevention of headache $e^{5,6,7,8}$. However, there are few facts where there is consensus among specialists. The use of drugs other than barbiturates, opioids and benzodiazepines, as well as the absence of psychiatric comorbidities, are considered favorable treatment outcomes when combined with the withdrawal of overused medications and a multidisciplinary treatment approach ${ }^{5,7,8}$.

Although medication-overuse headaches still have unknown underlying mechanisms, there is recent evidence of functional and structural abnormalities in specific brain areas that could identify and even predict those who will or will not respond to the treatment ${ }^{9,10,11,12}$. In addition, some studies have identified patients who are more prone to respond to withdrawal of

${ }^{1}$ Centro de Avaliação de Tratamento da Dor de Cabeça do Rio de Janeiro, Rio de Janeiro RJ, Brasil.

Correspondence: Abouch V. Krymchantowski; Rua Siqueira Campos, 43/1002; 22031-071 Rio de Janeiro RJ, Brasil; E-mail: abouchkrym@uol.com.br Conflict of interest: There is no conflict of interest to declare.

Received 06 May 2018; Received in final form 04 June 2018; Accepted 20 June 2018. 
offending medications ${ }^{9,12}$. With regard to strategies of treatment, recent available evidence emphasizes that outpatient detoxification may be sufficient for a successful withdrawal and for a resulting pattern of decreased consumption of overused medications $^{7,8,13}$. Despite that, it is unwise to count on advice only to achieve a sustained response without initiating prevention with one or more pharmacological agents ${ }^{8,13}$.

In this study, we aimed to compare and discuss the use of one or two, three, or four pharmacological agents for migraine prevention and medication-overuse headache in previous episodic or chronic migraineurs. It was not our intention to establish which specific combinations were better, but to evaluate the possibility that three or four drugs were more effective than one or two medications.

\section{METHODS}

This was a retrospective analysis comparing the preventive treatment strategies carried out in 149 consecutive patients, from a tertiary center, with medication-overuse headache according to the International Classification of Headache Disorders (ICHD-3 beta) ${ }^{14}$, who were evaluated between January and December 2014. The participants were consecutive patients seeking help at the premises and were not recruited to take part in a specific study. The complete study has already been published ${ }^{13}$, but no comparisons regarding prevention schemes or medications were performed until now.

The inclusion criteria were: 15 or more headache days per month for at least six months; 18-60 years of age; and a primary headache diagnosis of migraine or chronic migraine. The exclusion criteria were: inability to report clearly the baseline headache frequency; psychiatric comorbidities other than anxiety or depression; refusal to take part and sign the informed consent; and having used any preventive drug during the previous two months. Overuse of symptomatic medications was defined according to the ICHD-3 beta criteria ${ }^{14}$.

All patients were evaluated in long, initial consultations (mean time 1:10 hours), received extensive explanations regarding the diagnosis of migraine/chronic migraine and medication-overuse, were asked to fill out a detailed headache diary handed to them during the first consultation, and received in-depth written material regarding treatment strategies to be carried out from that day on. Returning consultations were scheduled for two, four and eight months later.

The sudden withdrawal of overused medications, the use of prednisone as a bridge medication during the first five or seven days for some patients, and the initiation of pharmacological headache prevention with one or more drugs were carried out with all patients. Adherence to the regimen and a decrease in headache frequency of more than $50 \%$ were compared at the second return visit (after four months), between the patients who received a prescription of one or two drugs, three drugs, or four drugs for prevention of headache. The medications were initiated immediately after withdrawal and were chosen based on the expertise of the treating physician, who prescribed the medication regimen based on the patient's characteristics, such as previous use of preventive agents, tolerability profile with drugs used in the past, physical features of patients (e.g., body weight) and even personal experience with drug combinations. As the patients were real-world patients and not subjects recruited to participate in the study, evidence-based strategies were not the primary driver for choosing the treatments. Therefore, the reasons why the treating physician chose a specific medication or group of medications was based on personal experience, degree of symptomatic medication overuse, history of previous use of medications and the patient's characteristics.

The comparison between different medications or group of medications prescribed as prevention strategies was not the objective of the original prospective study, which aimed at treating the patients as an entire population of medication-overuse headache sufferers and analyzing their evolution after specific time points (two, four and eight months). In this subsequent study, we retrospectively analyzed what was used for prevention and compared the subgroups of patients who simultaneously took one or two medications, three medications, and four pharmacological agents for prevention. Due to operational reasons, the patients' evolution at two months or at eight months after withdrawing and initiating the different preventive schemes were not compared with regard to headache frequency reduction and adherence between the different groups. However, analyzing outcomes after eight months would have been interesting to demonstrate the possible advantages in efficacy or the disadvantages in tolerability that one could expect when using more pharmacological agents.

The study was approved by an ethics committee and all patients signed a written informed consent (CAAE 0209.0.172.000-09). The patients were regular patients from a 30-year-old private headache center with more than 26,000 evaluated patients.

The statistical analysis was carried out using Pearson's chisquared test. The level of significance was estimated when $\mathrm{p} \leq 0.05$.

\section{RESULTS}

The main characteristics of the study population are described in Table 1. Of the 168 consecutive patients (31 men and 137 women) who met the inclusion criteria at the Headache Center of Rio de Janeiro, 19 were excluded. Eight (4.8\%) patients were found to have personality disorders, seven (4.2\%) patients declined to sign the informed consent and four $(2.4 \%)$ patients had used preventive medications during the previous 60 days. There were 149 patients (20 men and 129 women), aged between 18-60 years (mean 37.5 years) included in the study. All had migraine (with aura, without 
aura, both forms of migraine or chronic migraine) with medication overuse. The diagnosis of the primary headache was made based on a thorough history prior to the overuse of acute medications and not on the features presented during the initial visit when the patients were included in the study and educated about the headache.

The mean baseline frequency described by the patients was 24.8 headache days/month, the average headache history was 20.6 years (1-37 years) and the mean duration of having a headache on $\geq 15$ days/month was 4.8 years (0.5-32 years). All patients were overusing symptomatic medications, but 59 (39.6\%) were overusing more than one pharmacological class simultaneously. No patients were overusing barbiturates or opioids. Twelve (8\%) patients were using benzodiazepines less than eight days per month, while three patients were overusing these. The pharmacological classes of medications overused by the patients are presented in Table 2 .

An outpatient, abrupt withdrawal from overused medications was successfully carried out with all patients. The patients received different preventive treatment regimens starting on the sixth or eighth day. Additionally, they received the combination of a triptan plus an NSAID for the acute attacks, to be used in a maximum intake frequency of two days/week, which was clearly explained (Tables 3 and 4).

Table 1. Baseline characteristics of the 149 patients included in the study.

\begin{tabular}{lc}
\hline $\mathrm{N}$ & 168 \\
\hline Patients included & 149 \\
\hline Age in years (mean $\pm \mathrm{SD})$ & $37.5 \pm 9$ \\
Sex (male / female) & $20(13 \%) / 129(87 \%)$ \\
\hline Duration of headache in years (mean $\pm \mathrm{SD})$ & $20.8 \pm 11.7$ \\
Duration of headache $>15$ days/month in years (mean) & $0.5-32($ mean 4.8) \\
\hline Days of headache/month & $24.8 \pm 5.9$ \\
Days of symptomatic medication overuse/month & $22.6 \pm 6.4$ \\
Mean years of symptomatic medication overuse & $4.5 \pm 5.3$ \\
Diagnosis of primary headache & 131 \\
$\quad$ Migraine without aura & 15 \\
$\quad$ Migraine with and without aura & 3 \\
\hline Chronic migraine & \\
\hline
\end{tabular}

Table 2. Pharmacological classes overused by the study patients.

\begin{tabular}{lcc}
\hline Variable & N (\%) & Days/month overuse \\
\hline Combination analgesics + caffeine & $65(43.6)$ & 22.5 \\
Simple analgesics & $20(13.4)$ & 26 \\
Triptans & $65(43.6)$ & 24 \\
Combination analgesics + triptans & $19(12.7)$ & 17.5 \\
Combination analgesics + ergots & $17(11.4)$ & 23.2 \\
Combination analgesics + triptans + ergots & $8(5.4)$ & 18.7 \\
Benzodiazepines & $3(2)$ & 9.5 \\
More than one pharmacological class of medication & $59(39.5)$ & \\
\hline
\end{tabular}

Table 3. Bridge medications and acute treatments.

\begin{tabular}{|c|c|c|}
\hline Treatments prescribed & $\mathrm{N}$ & $\%$ \\
\hline \multicolumn{3}{|l|}{ Detoxification bridge } \\
\hline Prednisone 7 days ( $60 \mathrm{mg} 3$ days, $40 \mathrm{mg} 3$ days, $20 \mathrm{mg} 1$ day) & 44 & 29.0 \\
\hline Prednisone 5 days ( $60 \mathrm{mg} 3$ days, $40 \mathrm{mg} 2$ days) & 57 & 38.7 \\
\hline No Prednisone & 48 & 32.3 \\
\hline \multicolumn{3}{|l|}{ Acute treatment } \\
\hline Rizatriptan $10 \mathrm{mg}+$ sodium naproxen $550 \mathrm{mg}$ & 32 & 23.0 \\
\hline Rizatriptan $10 \mathrm{mg}+$ sodium diclofenac $50 \mathrm{mg}$ & 42 & 28.0 \\
\hline Rizatriptan $10 \mathrm{mg}+$ nimesulide $200 \mathrm{mg}$ & 19 & 13.0 \\
\hline Rizatriptan $10 \mathrm{mg}+$ lysine clonixinate $250 \mathrm{mg}$ & 9 & 6.0 \\
\hline Zolmitriptan $2.5 \mathrm{mg}+$ sodium naproxen $550 \mathrm{mg}$ & 29 & 17.0 \\
\hline Zolmitriptan $2.5 \mathrm{mg}+$ sodium diclofenac $50 \mathrm{mg}$ & 18 & 13.0 \\
\hline
\end{tabular}


Table 4. Preventive medications prescribed to the patients.

\begin{tabular}{|c|c|c|}
\hline Preventive treatment choices & $n=149$ & Dose range \\
\hline Sodium divalproate & 12 & $500-750 \mathrm{mg}$ \\
\hline Nortriptyline + topiramate & 14 & $20-30 m g+100-150 m g$ \\
\hline Topiramate + sodium divalproate & 8 & $100-150 m g+500 m g$ \\
\hline Nortriptyline + tizanidine* & 10 & $20 m g+8-12 m g$ \\
\hline Nortriptyline + tizanidine + flunarizine* & 46 & $20 m g+8-12 m g+2-3 m g$ \\
\hline Sodium divalproate + (nortriptyline + tizanidine)* & 16 & $500 m g+20 m g+8-12 m g$ \\
\hline Sodium divalproate + nortriptyline & 4 & $500 m g+20 m g$ \\
\hline Sodium divalproate + candesartan & 4 & $500 m g+8-16 m g$ \\
\hline$(\text { Nortriptyline }+ \text { tizanidine }+ \text { flunarizine }+ \text { pizotifen })^{*}$ & 14 & $20 m g+8-12 m g+2 m g+0.8-1.2 m g$ \\
\hline Topiramate + (nortriptyline + tizanidine + flunarizine)* & 18 & $100-150 m g+20 m g+8-12 m g+2 m g$ \\
\hline Topiramate + (nortriptyline + tizanidine)* & 2 & $100-150 m g+20 m g+8-12 m g$ \\
\hline Topiramate + candesartan & 1 & $100-150 m g+8-16 m g$ \\
\hline Prescription strategy & $\mathrm{n}$ & Headache frequency reduction $>50 \% p$-value \\
\hline One or two drugs & 23 & $54.8 \% \quad 0.09(2-d$ vs 3 and $4-d)$ \\
\hline Three drugs & 33 & $0.13(2-d$ vs $3-d)$ \\
\hline Four drugs & 11 & $0.98(2-d$ vs $4-d)$ \\
\hline
\end{tabular}

One hundred one patients (67.8\%) received prednisone during the first five or seven days as a bridge medication. No outcome differences were found regarding adherence between those who received the steroids and those who did not, as well as between the patients who received prednisone on five or seven days $(p=0.3032$, five days vs no prednisone; $p=0.639$, seven days vs no prednisone).

Regarding adherence among those who received one or two, three, or four preventive medications, no differences were encountered ( $p>0.6)$. After four months, 40 patients were lost to follow up (30 at two months and 10 more after four months). The average headache frequency was, respectively, 7.6 (among those patients who returned after 4 months) and 11.2 (considering all patients who were initially included) headache days per month.

At four months, among the 109 patients remaining under treatment, 42 patients $(38.5 \%$ of all patients still under treatment and $66.7 \%$ of those who received up to two medications) were taking one or two medications for prevention, 47 (43\% of all patients still under treatment and $73 \%$ of those who received three medications) were taking three pharmacological agents for prevention and $20(18.3 \%$ of all patients still under treatment and $62 \%$ of those who received four medications) were using four agents for preventing headache attacks.

With regard to headache frequency reduction, respectively, $23(54.8 \%)$ of the one-to-two-drug takers, 33 (70\%) of the threedrug takers and 11 (55\%) of the four-drug takers had a greater than $50 \%$ headache frequency reduction. The comparisons between the one-to-two-drug takers with the three-drug takers and with the four-drug takers were not significant (respectively, $\mathrm{p}=0.13$ and $\mathrm{p}=0.98$ ). However, there was a tendency toward significance when a comparison was made between the group of one-to-two-drug takers versus the three-drug takers and the four-drug takers together $(p=0.09)$. It is possible that a greater number of patients taking one to two drugs compared with more patients taking three drugs, or four drugs may have revealed the superiority of using more than two drugs for the treatment of medication-overuse headache (Table 4).

\section{DISCUSSION}

This was a retrospective comparison between three different strategies of prevention for medication-overuse headache patients who started treatment after interrupting their overuse of symptomatic medications. The study has many methodological flaws, but it was performed with real-world patients attending a tertiary referral center, which may have powered the results. However, relying on a patient's information to record baseline headache frequency and the choice for specific treatment regimens based on the treating physician expertise limits the conclusions from the observed results. In addition, as well known, open retrospective studies with medications are definitively not sufficient for a treatment paradigm change ${ }^{15,16}$.

Moreover, there is not yet consensus on the need for initiating prevention after withdrawal. Grande et al. ${ }^{17}$ presented a series of patients who were simply given information on the role of medication-overuse in the development of headache on more than 15 days per month. In a specific population of patients from a Norwegian University hospital, $92 \%$ of the sufferers had chronic tension-type headache and 53\% had migraine co-occurrence. Most reduced the pattern to episodic headache after 1.5 years with decreasing consumption of symptomatic headache medication from 22 to six days per month ${ }^{17}$. Tassorelli et al. ${ }^{8}$ also studied medication-overuse headache patients and carried out a similar strategy of treatment to ours. However, in their sample of 376 medication-overuse headache patients, $17.1 \%$ did not take preventive agents ${ }^{8}$. 
On the other hand, Munksgaard et al. ${ }^{18}$ reported that combining detoxification, advice and prevention is an effective strategy to obtain treatment adherence and reduction of headache frequency to episodic headache but, as with our patients from the present study, there was not a preponderance of opioid and barbiturates overusers ${ }^{18}$.

However, one might argue why two, three, or even four drugs were used when monotherapy is suggested in the text books ${ }^{19,20}$. This may be a correct protocol but, among specialists practicing in tertiary centers, combination is the rule ${ }^{21}$. Additionally, migraine is a complex disease involving different neurotransmitter systems and a rational combination of medications acting on different receptors and sites seems to be a plausible approach ${ }^{22}$.

The few available studies on combination therapies for migraine have not proven the advantage of using two or more pharmacological agents ${ }^{23}$. However, performing such studies depends on pharmaceutical company financial support and reduction of drugs is not the usual desired outcome in the industry.

In addition, data on the experiences of numerous headache specialists just corroborate the common approach of combining drugs in clinical practice ${ }^{24,25,26}$. It is true that using more drugs may impair adherence or tolerability, despite recent evidence to the contrary ${ }^{27}$. This was not the case with our results, which did not show differences in adherence or in the occurrence of side effects among groups, although tolerability was not compared between the patients taking more or less medications.

It is worthwhile to mention that this study does not suggest the use of combinations in all patients. In fact, as suggested by the available literature, monotherapy should be the recommended approach, especially in primary care, or in patients who have not used preventive medications in the past ${ }^{7,19,20}$. In addition, combining drugs requires a deeper knowledge of the usual medications, which may not be the case in all treating professionals, especially those from other medical specialties.

We were not able to demonstrate the clear superiority of a specific number of drugs compared to one or two medications, but this raises the discussion that medications actingin different sites simultaneously may result in a broader modulation and, therefore, better outcome parameters. Moreover, migraine preventive agents can be used effectively even in lower doses than their primary use for other pathological conditions, which counteracts higher toxicity ${ }^{19,20,24,26}$. Prospective controlled studies comparing monotherapy with a rational combination of drugs in real-world settings and bigger patient populations are warranted.

\section{References}

1. Agosti R. Migraine Burden of Disease: From the patient's experience to a socio-economic view. Headache. 2018 May;58 Suppl 1:17-32. https://doi.org/10.1111/head.13301

2. Andrasik F, Grazzi L, Usai S, Kass S, Bussone G. Disability in chronic migraine with medication overuse: treatment effects through 5 years. Cephalalgia. 2010 May;30(5):610-4. https://doi.org/10.1111/j.1468-2982.2009.01932.x

3. Kristoffersen ES, Lundqvist C. Medication-overuse headache: a review. J Pain Res. 2014 Jun;7:367-78. https://doi.org/10.2147/JPR.S46071

4. Scher Al, Stewart WF, Liberman J, Lipton RB. Prevalence of frequent headache in a population sample. Headache. $1998 \mathrm{Jul}-$ Aug;38(7):497-506. https://doi.org/10.1046/j.1526-4610.1998.3807497.x

5. Lipton RB. Risk factors for and management of medication overuse headache. Continuum (Minneap Minn). 2015 Aug;21 (4 Headache):1118-31. https://doi.org/10.1212/CON.00000000000000216

6. Schwedt TJ, Chong CD. Medication overuse headache: pathophysiological insights from structural and functional brain MRI research. Headache. $2017 \mathrm{Jul} ; 57(7): 1173-8$. https://doi.org/10.1111/head.13037

7. Russell MB, Lundqvist C. Prevention and management of medication overuse headache. Curr Opin Neurol. 2012 Jun;25(3):290-5. https://doi.org/10.1097/WC0.0b013e328352c431

8. Tassorelli C, Jensen R, Allena M, De Icco R, Sances G, Katsarava Z et al.; the COMOESTAS Consortium. A consensus protocol for the management of medication-overuse headache: evaluation in a multicentric, multinational study. Cephalalgia. 2014 Aug;34(9):645-55. https://doi.org/10.1177/0333102414521508

9. Krymchantowski AV, Jevoux CD. Medication-overuse headache. Despite the advances in understanding it, treatment evidence still lacks. Expert Rev Neurother. 2017 Nov; 17(11):1055-8. https://doi.org/10.1080/14737175.2017.1374173
10. Lai TH, Chou KH, Fuh JL, Lee PL, Kung YC, Lin CP et al. Gray matter changes related to medication overuse in patients with chronic migraine. Cephalalgia. 2016 Dec;36(14):1324-33. https://doi.org/10.1177/0333102416630593

11. Riederer F, Marti M, Luechinger R, Lanzenberger R, von Meyenburg J, Gantenbein AR et al. Grey matter changes associated with medication-overuse headache: correlations with disease related disability and anxiety. World J Biol Psychiatry. 2012 Oct;13(7):517-25. https://doi.org/10.3109/15622975.2012.665175

12. Chanraud S, Di Scala G, Dilharreguy B, Schoenen J, Allard M, Radat F. Brain functional connectivity and morphology changes in medicationoveruse headache: clue for dependence-related processes? Cephalalgia. 2014 Jul;34(8):605-15. https://doi.org/10.1177/0333102413519514

13. Krymchantowski AV, Tepper SJ, Jevoux C, Valença M. Medicationoveruse headache: protocols and outcomes in 149 consecutive patients in a tertiary Brazilian center. Headache. 2017 Jan;57(1):87-96. https://doi.org/10.1111/head.12970

14. Headache Classification Committee of the International Headache Society (IHS). The international classification of headache disorders, 3rd edition (beta version). Cephalalgia 2013;33(9):629-808. https://doi.org/10.1177/0333102413485658

15. White C, Bailar JC 3rd. Retrospective and prospective methods of studying association in medicine. Am J Public Health Nations Health. 1956 Jan;46(1):35-44. https://doi.org/10.2105/AJPH.46.1.35

16. Hochman B, Nahas FX, Oliveira Filho RS, Ferreira LM. [Research designs]. Acta Cir Bras. 2005;20 Suppl 2:2-9. Portuguese. https://doi.org/10.1590/S0102-86502005000800002

17. Grande RB, Aaseth K, Benth JŠ, Lundqvist C, Russell MB. Reduction in medication-overuse headache after short information. The Akershus study of chronic headache. Eur J Neurol. 2011 Jan;18(1):129-37. https://doi.org/10.1111/j.1468-1331.2010.03094.x 
18. Munksgaard SB, Bendtsen L, Jensen RH. Treatment-resistant medication overuse headache can be cured. Headache. $2012 \mathrm{Jul}-$ Aug;52(7):1120-9. https://doi.org/10.1111/j.1526-4610.2012.02191.x

19. Mathew NT, Tfelt-Hansen P. General and Pharmacologic Approach to Migraine Management. In: Olesen J, Goadsby PJ, Ramadan NM, Tfelt-Hansen P, Welch KM, editors. The Headaches. 3rd ed. Philadelphia: Lippincott Williams \& Wilkins; 2006. p. 433-40.

20. Silberstein SD, Freitag F, Bigal ME. Migraine treatment. In: Silberstein SD, Lipton RB, Dodick DW, editors. Wolff's headache and other head pain. 8th ed. Oxford: University Press; 2008. p. 177-292.

21. Krymchantowski AV, Jevoux CC. The pharmacological treatment of migraine in Brazil. Headache. 2015 Feb;55 Suppl 1:51-8. https://doi.org/10.1111/head.12513

22. Krymchantowski AV, Bigal ME. Polytherapy in the preventive and acute treatment of migraine: fundamentals for changing the approach. Expert Rev Neurother. 2006 Mar;6(3):283-9. https://doi.org/10.1586/14737175.6.3.283
23. Silberstein SD, Dodick DW, Lindblad AS, Holroyd K, Harrington M, Mathew NT et al. Randomized, placebo-controlled trial of propranolol added to topiramate in chronic migraine. Neurology. 2012 Mar;78(13):976-84. https://doi.org/10.1212/WNL.0b013e31824d5846

24. Diener HC, Charles A, Goadsby PJ, Holle D. New therapeutic approaches for the prevention and treatment of migraine. Lancet Neurol. 2015 Oct;14(10):1010-22. https://doi.org/10.1016/S1474-4422(15)00198-2

25. Guilbot A, Bangratz M, Ait Abdellah S, Lucas C. A combination of coenzyme Q10, feverfew and magnesium for migraine prophylaxis: a prospective observational study. BMC Complement Altern Med. 2017 Aug;17(1):433. https://doi.org/10.1186/s12906-017-1933-7

26. Krymchantowski AV. Acute treatment of migraine: breaking the paradigm of monotherapy. BMC Neurol. $2004 \mathrm{Jan} ; 4(1): 4$. https://doi.org/10.1186/1471-2377-4-4

27. Dozza AL, Krymchantowski AV. Adherence to migraine treatment does not depend on the number of prescribed medications. Arq Neuropsiquiatr. 2013 Mar;71(3):171-3. https://doi.org/10.1590/S0004-282X2013000300008 